\title{
Cultura y dignidad en América Latina
} Descolonialidad de la desigualdad social

Recibido: 06/10/2016

Aprobado: 28/11/2016
Julio Mejía Navarrete

Universidad Nacional Mayor de San Marcos

$<$ jvmena1@hotmail.com >

\section{RESUMEN}

El artículo analiza algunas cuestiones iniciales sobre el desarrollo del conflicto cultural que define el ritmo de la vida contemporánea de América Latina. Emerge una nueva subjetividad que niega las formas dominantes de pensar la sociedad en términos de las diferencias y emerge una episteme en función de la igualdad social.

Palabras clave: modernidad global, cultura de la desigualdad social, cultura de la dignidad

\section{Culture and dignity in Latin America. Discoloniality of social inequality}

\begin{abstract}
The article analyzes some initial questions on the development of the cultural conflict that defines the pace of the contemporary life of Latin America. It emerges a new subjectivity which denies the dominant forms of thinking society in terms of the differences and emerge an episteme in function of social equality.
\end{abstract}

KEYworDs: Global modernity, culture of social inequality, culture of dignity. 


\section{Introducción}

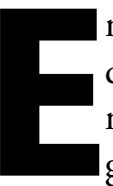
n América Latina las simbólicas de la desigualdad social extrema se han impuesto abiertamente como resultado de la modernización global. Se reproduce culturalmente un orden social neoliberal sustentado en mayores jerarquías y diferencias sociales. Sin embargo, en las últimas décadas irrumpen inéditas formas culturales sustentadas en la dignidad, en la fuerza de los valores de la igualdad social. Desde los orígenes de la civilización, a contracorriente en las últimas décadas se desarrolla un pensamiento que permite imaginar un orden societal instaurado en la igualdad social.

Pareciera que el conflicto cultural define el ritmo de la vida social contemporánea de América Latina. Emerge una nueva subjetividad que pone en cuestión las formas dominantes de pensar la sociedad y desarrolla una episteme en función de la igualdad social. Hoy germina un nuevo espíritu de descolonialidad de la reproducción cultural de la desigualdad social.

El malestar en la cultura (1930) de Sigmund Freud formuló la cuestión del conflicto cultural como núcleo esencial de la dinámica civilizatoria que cobra vigencia inusitada en la actualidad. El desarrollo cultural era entendido como una transacción entre seguridad y libertad, los contemporáneos de Freud estaban dispuestos a ceder seguridad para obtener más libertad. De esa forma, la historia era vista como el desarrollo de la búsqueda de mayor libertad, de la propagación de la cultura de la libertad. En la actualidad todo se ha modificado, las gentes estarían dispuestas a ceder parte de la libertad a costa de un discurso de seguridad por el crecimiento exponencial de violencia y la desigualdad social. La historia reciente se encuentra signada por profundas transformaciones sistémicas y por el desarrollo de un conflicto cultural entre la persistencia simbólica de las inequidades sociales y la insurgencia de un pensamiento de la dignidad.

En este artículo pretendemos desarrollar algunas proposiciones iniciales que permitan organizar el debate entre la cultural de la desigualdad social y la emergencia de la episteme de la dignidad en América Latina. El artículo se divide en cuatro partes. La primera sección expone las condiciones sociales de la desigualdad social, destacamos la relación entre la modernidad tardía y el incremento de las diferencias sociales. La segunda describe una cultura oscurantista basad en la hegemonía del individualismo extremo, el pensamien- to del miedo y la "razón cínica" que condicionan el desarrollo de las conductas de desigualdad y exclusión en América Latina. La tercera resalta la incidencia de los movimientos de la sociedad que gestan un nuevo sentido histórico de igualdad y expresan otro ideal del orden societal. Finalmente, a partir de las modificaciones substanciales de la modernidad y el desarrollo de los movimientos de la sociedad se expone la emergencia de la cultura de la dignidad en América Latina.

\section{Sociedad, modernidad global y desigualdad}

El actual proceso cultural se encuentra definido por la dinámica de transformaciones profundas del patrón moderno global. Wallerstein (2010) define a las primeras cinco décadas del siglo XXI como un momento de transición, en que las tendencias seculares se alejan del equilibrio y entran en un estado de bifurcación e incertidumbre. El sistema-mundo moderno después de más de 500 años ha ingresado en un periodo de fluctuaciones rápidas y constantes. La modernización capitalista global como nunca en su historia está expandiéndose a un ritmo exponencial, por primera vez una formación social cubre todos los rincones del planeta. Proceso abierto desde la mitad de la década del setenta que viene produciendo cambios estructurales en la organización de la sociedad.

En ese sentido, la dinámica de las mutaciones de la globalización no solo significan efectos coyunturales en la dinámica de la modernidad, sino más bien implica su misma reconstrucción, Quijano (2014a, 852) denomina a este nuevo período histórico de "crisis raigal de la colonialidad global del poder". En América Latina la modernidad global está llegando a sus límites y definen una dinámica de desequilibrios radicales, el orden no solo explota y domina a las gentes, sobre todo, delinea desigualdades sociales abismales que "Destruye la naturaleza" y "destruye al otro excluyendo grandes poblaciones" (Hinkelammert 2003, 66).

En particular, el desarrollo de la sociedad moderna global se correlaciona con la gestación de una nueva revolución tecnológica, que empieza modificarla. La expansión exponencial del capital determina una situación de amenaza feroz sobre la Tierra, produciendo históricamente la mayor brecha entre la sociedad y la naturaleza, llevando el conflicto a niveles catastróficos entre una acumulación ilimitada del capital frente a los recursos definidos del planeta, el resultado: la crisis 
climática global pone en peligro la propia vida. En los andes peruanos se han perdido irremediablemente el 42.64\% de los glaciares de las cordilleras por la impacto del calentamiento global (MINAGRI-ANA 2014). Actualmente está en desarrollo la sexta extinción a gran escala de la vida en la tierra, la ratio es hasta 100 veces más alto que la tasa natural (Ceballos et al. 2015) y el año 2015 ha sido el de mayor temperatura de los que se tiene registro histórico (NASA 2015). Parecería que el equilibrio autopoiético de la Tierra se ha quebrado por la influencia depredadora de la modernización de los últimos cinco siglos, poniendo en peligro toda forma de existencia en los próximos 100 años. Se ha generado una diferenciación abismal entre los intereses del orden societal modernizante y la existencia de la naturaleza.

El desarrollo de la automatización de los procesos productivos y la reorganización posfordista del trabajo implican un cambio decisivo en la sociedad, pareciera que la relación capital-asalariado llega a su límite, la modernidad capitalista ya no logra generar masivamente trabajo asalariado. Aunque el sistema moderno puede seguir reproduciéndose, lo hace recurriendo cada vez más a la flexibilidad laboral, precarización, desempleo estructural, la extensión de la pequeña producción mercantil y de formas que lindan con relaciones paraesclavistas y serviles ${ }^{1}$. A las viejas diferencias ligadas con a la dominación de raza/étnicas, género y explotación de clase, en la actualidad se ańaden y combinan los mecanismos informales que cubren formas irregulares, precarias, ocultas e ilegales de violencia y exclusiones directas como el trabajo infantil, redes y mafias de tratas, tráficos de mujeres, etc. (García Canclini 2007). El resultado de la modernización global neoliberal es la abismal concentración de recursos y riquezas que lleva al crecimiento incesante de la desigualdad social extrema (Piketty 2015). América Latina sigue siendo el continente de mayor disparidad social, en el mundo el $10 \%$ de la población se apropiada del $88 \%$ de la riqueza y el $50 \%$ más pobre posee únicamente el $1 \%$ del total (Castells 2015). De esa manera, el actual sistema moderno capitalista ya no puede seguir controlando a la población por medio de relaciones asalariadas $\mathrm{y}$, de manera directa, mediante el control del cuerpo y de

1 En el Perú este proceso se expresa crudamente en que el $70 \%$ de los trabajadores se encuentran en el sector informal y en América Latina los jóvenes que ni trabajan ni estudian representan más 20 millones de personas (De Hoyos, Rogers y Székely 2016). Realidad que afecta a los países desarrollados, en Francia el 25\% de personas menores de 25 ańos se encuentran desempleadas y en Espańa los datos se acercan al 50\% de los jóvenes. las propias personas en los viejos espacios panópticos. Más bien la modernidad global se desplaza principalmente hacia la dominación de la subjetividad y el control de las mentes de la población, erigiendo el conflicto epistémico en el foco estructural de su desarrollo.

En general, la «crisis raigal» de la modernidad global traza una posibilidad funesta en la historia, la propagación continúa de las desigualdades extremas en la humanidad y de esta con la naturaleza. Escenario que no permite tener la esperanza de erradicar la miseria, ni liberar el sufrimiento de la humanidad. Al contrario, la promesa libertarias de la modernidad han sido incumplida en América Latina y el mundo, más bien pareciera que marcha a la expansión de la modernidad pero sin los grandes logros que el modernismo trazó originariamente, viene ocurriendo una modernización sin precedentes del planeta aunque sin las aspiraciones libertarias de la modernidad.

Todos los aspectos de la existencia social se encuentran oscurecidas y corroídos por el crecimiento violento de la desigualdad social. El mundo se vuelve un lugar inhabitable, que reposa en una cultura de la marginación y exclusión de las mayorías poblaciones de América Latina.

\section{Cultura de la desigualdad social}

La cultura de la desigualdad social es la manifestación del orden neoliberal global, pensamiento que condiciona e induce a la reproducción de la diferenciación social en el mundo contemporáneo. La cultura de la desigualdad implica la naturalización de la abismal desigualdad social, distinguiéndola como la forma normal y la única manera de organizar jerárquicamente la sociedad, y conlleva la aceptación resignada de las diferencias sociales como parte inalienable de la distribución del poder en el mundo globalizado.

Sin embargo, en América Latina la verdadera matriz de la desigualdad social moderna proviene de la dominación de la colonialidad que se estructura en función de la clasificación racializada de la población, en términos de la raza y la etnicidad inferiorizadas, asentada en la supuesta superioridad de los valores occidentales, que convierten a las poblaciones nativas en seres subhumanos, bárbaros, indígenas, negros o mestizos, indignos y desprovistos de derechos. Ese fue el patrón colonial de la que surgieron las sociedades actuales de América Latina. La cuestión central de la 
reproducción cultural de la desigualdad social fundada en el constructo mental de la colonialidad se entremezcla con las actuales formas culturales de la modernidad neoliberal global.

En efecto, hoy la situación del incremento exponencial de la desigualdad social se vincula estrechamente con la expansión del crecimiento económico en América Latina (PNUD 2013). La desigualdad social polarizada y sus manifestaciones simbólicas se tornan en componentes estructurales, se transforman en partes integrantes del patrón moderno globalizado de América Latina

La cultura moderna reproduce "la irracionalidad de lo racionalizado", donde las relaciones mercantiles y las inequidades sociales vastas amenazan la vida humana y la naturaleza, se transforman en la condición de una "muerte colectiva". En América Latina la modernidad global produce irracionalidad, pareciera que la razón instrumental medios-fin está llegando a sus límite y entra en un dinámica de crisis, no solo se explota y domina como nunca en la historia de la humanidad, sobre todo, produce desigualdades extremas, el sistema social genera principalmente "violencia más allá de todo cálculo" y muerte permanente (Hinkelammert \& Mora 2005). La cultura de la la desigualdad social expresa un mundo simbólico donde el individualismo extremo la incentiva, infunde miedo y la justifica cínicamente.

En la modernidad global la propagación del individualismo extremo solivianta la desigualdad social. El sujeto atomizado pasa a ser el núcleo sobre el cual gira toda la vida social en América Latina. El sujeto se ha librado de los últimos constreńimientos estructurales socializantes que impedían su total emancipación: la disminución del peso social del Estado, de las clases sociales, del poder de la vecindad, la familia, las grandes ideologías dejan de ser los principales vehículos de proyectos históricos, las creencias utópicas se desacreditan, pareciera que se desarrolla una sensación de "era del vacío" (Lipovetsky 2003), se han evaporado los constreñimientos sociales y éticos del individualismo en la sociedad global. En América Latina hoy se desarrolló un deterioro constante de los vínculos sociales, de las solidaridades y, en consecuencia, se genera una dinámica de atomización que envuelve todos los aspectos de la vida social, los comportamientos tienden a aislar a las personas. En general, la sociedad se define por el "egocentrismo, que reduce el horizonte al interés personal” (Morin 2011, 57), únicamente el otro existe como obstáculo o es un recurso para lograr el provecho individualista, desaparece toda consideración a la comunidad y toda causa común.

La cultura de privatización y el individualismo extremo ocurren en un mundo de incesante violencia y destrucción del "capital social" (Bourdieu 1980), donde el afecto y la confianza con los otros resultan disfuncionales para la sociedad y se pierde la energía colectiva que puedan generar las interacciones de respeto, disfrute de la compañía de los otros y la fortaleza de la comunidad. La sociedad globalizada privatiza y mercantiliza, separa a los individuos y hace que las emociones con los demás se transformen en mercancía.

La desestructuración del tejido social y el debilitamiento de la acción estructurante de las instituciones de la sociedad, dejan a las personas sometidas a la acción individual y a un imaginario cuya máxima define que para enfrentar el mundo hay que hacerlo solos. La cultura transforma la vida social en función de la agresividad individualista, no interesa los otros, menos la desigualdad social. El mayor exponte del liberalismo en América Latina Hernando de Soto (2016) lo expresa claramente, lo esencial no es la desigualdad "porque tan pocos tienen tanto", sino es el individualismo emprendedor el combustible central de la reproducción de la vida social.

En América Latina la producción de un imaginario de la desigualdad social creciente, comprende como uno de sus aspectos más destacados el desarrollo de una simbólica del miedo y temor al otro de la modernidad global. Precisamente, los otros son los marginados y excluidos de la vida social porque son individuos superfluos, sin posibilidades de (re)incorporarse a la fuerza laboral y al consumo, son los nuevos pobres, no por estar sin trabajo sino, principalmente, porque son los expulsados del mercado (Bauman 2000).

La vida social en la región se trastoca cada vez más en inhumana y menos propicia para el contacto entre las personas, es un espacio donde circula las formas extremas de la desigualdad social, el desempleo, la discriminación, la pobreza, la informalidad, corrupción, el narcotráfico y la criminalidad. Lo que produce es un estado de miedo frente al otro, angustia e incertidumbre de que algo malo está ocurriendo o puede ocurrir, las calles, las plazas, los mercados y espacios públicos son recintos de los otros que infunden "incertidumbre, inseguridad y vulnerabilidad", sentimientos profundos de peligro, temor, angustia permanente y en donde la confianza a los otros y a las instituciones se han evaporado (Bauman 2008). Transformación profunda de la 
existencia social que induce al agotamiento de la idea del futuro como promesa y se reemplaza por la imagen de lo próximo como algo inseguro, directamente relacionado con la amenaza y el riesgo (Beck 1997).

En este marco de ideas, el otro además de aparecer como sospechoso, peligroso y del cual es preferible alejarse, inciden fundamentalmente en el desarrollo de una concepción basado en la "negación de la subjetividad", en la construcción de la imagen del otro como un ser humano indigno, humillado, carente de derechos, al que se puede dominar y en caso de resistencia someter (Bauman 2011, 83). Cultura que predispone la inhabilitación de la humanidad del otro, al tratar de borrar su capacidad de interlocutor, de diálogo, quitándole la voz y buscando su transformación en un ser silenciado.

Asimismo, es una cultura que le substrae el "rostro" al otro, para despojarlo de todos los elementos de su identidad excepto el ser excluido, expropia sus facultades morales, los convierte en indignos de respeto y los privado de sus derechos para posibilitar la marginación, criminalización y represión. Marginación porque habilita la elaboración de un discurso sobre la división extrema de la sociedad, que alude a una forma diferenciación del ser, al otro le corresponde una forma de exclusión por la carencia de identidad con el trabajo asalariado y el consumo, únicamente le corresponde la imagen peyorativa de un ser disfuncional, pobre y cholo. Criminalizar es una forma de estigmatizar al otro para marginarlo y ejercer la posición de poder, con la intención de reprimirlo, al imputarle una etiqueta subjetiva de rechazo, apartarlo, violentarlo y hasta encarcelarlo (Mejía 2014, 85). La modernidad global traduce la cultura del miedo que elabora un pensamiento de la desigualdad social que "destruye al otro excluyendo grandes poblaciones".

El desarrollo del individualismo, la devastación del capital social y la destrucción de la confianza trae su sustitución por el cinismo². La modernidad global desarrolla una cultura cínica que no tiene el tapujo de aceptar abiertamente lo que antes ocultaba, la desigualdad extrema y sus correlatos de injusticia, informalidad, violencia, corrupción y falta de humanidad, cultura que desecha todo sentimiento de culpa al borrar

2 Los orígenes del cinismo se remontan a la Grecia antigua, expresada en la escuela filosófica liderada por Antístenes, que reivindicaba la vida natural, sin normas, ni convenciones, aspiraba a una existencia sobria, sin ornamentos, ni artificios y se buscaba la autenticidad. Contario al cinismo difuso de la modernidad tardía, véase Sloterdijk (2003). el dolor que genera la idea de haber perjudicado a los otros (Bauman y Donskis 2013).

La cultura cínica posibilita que pueda intensificarse la modernización y el crecimiento económico descomunalmente sobre América Latina y, a la vez, descaradamente no se tiene reparos morales en destruir la naturaleza y las personas. En la vida social se extiende el influjo del "todo vale" que deriva en el comportamiento cínico, el individuo busca imponerse porque piensa que tiene todo el derecho de hacerlo, sin pensar en los otros e incluso apelando a la violencia desembocada (Ubilluz 2006, 74-75). La afirmación de que "nadie cree en nadie" parece haberse convertido en el principio central para salir adelante, la insensibilidad moral se impone en la lucha de la vida diaria. El cinismo es la otra cara del hiperindividualismo globalizado.

La generalización de la razón cínica en la modernidad global de América Latina es la preponderancia del "estado de guerra" (Dussel 2002/2003) entre las personas, la excepcionalidad de la beligerancia individualista se convierte en parte intrínseca de la vida en América Latina, es el reino del enfrentamiento de individuos egoístas, en la que el otro es aniquilado y vencido a cualquier precio. En el "estado de guerra" la sociedad se vuelve un conjunto de agresivos egos que compiten con la finalidad suprema de autopromoverse a costa de los demás, en la que predomina la simbólica del ventajismo individual, el afán de lucro desbocado, la rudeza y el pragmatismo que llega a su forma de descarada e indolente, sin importar nada. Es la negación de todo derecho del otro sin reparo y miramiento alguno. Cultura que establece que la vida social y la diferenciación social es la práctica de vencer por todos los medios e imponer los intereses privados y egoístas sin pensar que algo se interpone.

El cinismo es el uso del poder absoluto, arbitrario y sin límites, simplemente los demás, las gentes no interesan, es el dominio de la cultura de la desesperanza, del "sálvese quien pueda" y el "después de nosotros el diluvio" (Hinkelammert 2001,105-111). El cinismo se revela como la forma moderna global de reproducción y justificación de la dominación e inferiorización de las gentes por medio de la fuerza, sobre las conductas individuales hasta las prácticas de dominación de las corporaciones y los países, que someten y controlan apelando a prácticas directas, desvergonzadas y descaradas, sin un mínimo de remordimiento ético: la trata de blancas, el trabajo infantil, el trabajo precario, las nuevas formas esclavizadas del trabajo, hasta la muerte 
de las poblaciones. La "razón cínica" permite la estructuración societal de la desigualdad extrema sin que nadie se inmute y conmueva, está permitido el "todo vale" sin pena y escrúpulo. Es la cultura oscurantista de la época de la globalización.

En América Latina la cultura de la desigualdad social fundada en la colonialidad se entremezcla con la difusión acelerada de expresiones neoliberales del orden global, que dominan la episteme de las personas en la acción individualista. Cultura que produce un estado de miedo frente al otro, el excluido y pobre, generalizando un sentimiento de peligro, temor, angustia permanente y donde la confianza tiende a desaparecer. El resultado es el desarrolla de una cultura cínica que desecha toda culpa, que suprime la aflicción de dolor que inducía la idea de haber perjudicado a los otros y en forma descarnada justifica toda forma de desigualdad y exclusión social.

\section{Movimientos de la sociedad}

En el contexto de cambios sistémicos, son los nuevos movimientos de la sociedad los que vuelven a instituir valores culturales libertarios que cuestionan el patrón epistémico moderno, alterando las formas de pensamiento de la sociedad sobre sí misma, germinando un nuevo sentido histórico que empieza a revisar la subjetividad de la desigualdad social, trayendo una nueva propuesta moral que expresa otro ideal del orden societal, que prescribe un rumbo alternativo y alumbra el sentido de la vida interior de las personas. Procesos que trazan la aspiración societal que pueda instituirse con las máximas de justicia societal, libertad y autonomía (Mejía 2016).

Los movimientos de la sociedad señalan un nuevo imaginario histórico a contracorriente de la dominación, explotación y desigualdad del mundo actual. Pareciera que los nuevos movimientos de la sociedad anuncian la posibilidad de un "Tiempo-eje" de grandes modificaciones que posibiliten pensar en un mundo estructurado en un orden social donde la igualdad social y la dignidad humana sean la raíz de su constitución. Un "Tiempo-eje" semejante al de los siglos VIII y $\mathrm{V}$ a. C. que posibilitaron el surgimiento en múltiples espacios del mundo, las ideas de Confucio en la China, el budismo en India y el desarrollo del pensamiento griego que sentaran las bases del pensamiento especulativo actual (Jaspers 1968).
En las últimas décadas se ensayan diversas respuestas en América Latina. Indígenas, afros, negros, etnicidades y grupos sociales diferenciados y subordinados cuestionan la idea de la raza, etnicidad, todas las formas de clasificación y jerarquización social. Poblaciones y comunidades se enfrentan a la mercantilización del territorio y la ecología para plantear la defensa de las condiciones de existencia y sobrevivencia del mundo. Las redes de "indignados" que se extendieron desde la primavera árabe, Europa, el movimiento "occupy" en Estados Unidos, los movimientos estudiantiles de Chile, \#Yosoy132 de México, "rebelión de los pulpines" en el Perú, las protestas del Brasil instalan las demandas de igualdad social como la aspiración central frente al "1\% más rico" de la sociedad ${ }^{3}$. De la misma forma, trabajadores, mujeres, jóvenes, homosexuales, pacifistas, anti-utilitarios, antiglobalización y otros desarrollan un conjunto de idearios, demandas y medidas de lucha que apuntan al reconocimiento de los derechos humanos, de los derechos las mujeres, de los derechos de los homosexuales, de los derechos de la paz, solidaridad, reciprocidad y, en general, a la construcción de una sociedad más igualitaria y justa.

Los movimientos de la sociedad son la fuerza central de la transformación contemporánea que posibilita a la diversidad de actores sociales su conversión en sujetos con autonomía y proyectos inéditos que permitan modificar las líneas maestras de la estructuración desigual de la sociedad, al margen de las instituciones existentes de la modernidad global. Se abre un momento histórico de transformación colosal de la cultura, pierde legitimidad el viejo constructo mental sobre las desigualdades racial/étnica, de género, clase, de exclusiones abiertas y de la degradación del planeta, se cuestionan las antiguas formas categoriales que facilitan el pensar y organizar históricamente el orden presente del mundo en una cultura de la desigualdad (Bauman 2014, 83-91).

En América Latina desde fines del siglo XX por la crisis de la modernidad globalizada y el desarrollo de los nuevos movimientos de la sociedad, empieza a cambiar el sentido del orden y las mentes de las personas ponen en paréntesis los fundamentos de la legitimidad de la desigualdad social, la legitimidad de la idea de la raza/etnicidad, la legitimidad de la idea de género y la legitimidad de la cosificación del medio ambiente,

3 Puede consultarse Castells (2014), Zibechi (2015), Sandobal, R. (2015), Rojas (2012), Aguilera (2016), Fernández-Maldonado (2015), González y Schneider (2016). 
más bien se instituyen valores, ideas y la emergencia de una subjetividad que impugna el subterfugio de la naturalización de toda forma de desigualdad social y afirman posibilidades de imaginar un mundo cimentado en la igualdad social de las gentes y en la unidad de la sociedad con el universo.

\section{Cultura de la dignidad}

El devenir del sistema moderno global está generando un campo de disputa cultural muy intenso. Los nuevos movimientos de la sociedad objetan y deslegitiman los valores y los poderes de la reproducción cultural de la desigualdad social y, a la vez, trazan en el largo plazo el florecimiento de ideas simbólicas e imaginarios de un orden sustentado en la dignidad, en la igualdad social (Kristeva 1999). En América Latina se ha abierto una etapa de modificaciones del pensamiento, la vieja "cultura de la dominación" y de la desigualdad social se encuentra en cuestionamiento por el desarrollo de la cultura de la dignidad. Es una etapa de emergencia epistémica que contradicen la hegemonía del pensamiento neoliberal.

La crisis del sistema moderno global y los movimientos de la sociedad en América Latina están llevando a la pérdida de legitimidad de las diferencias sociales, cuyos argumentos ya no se aceptan, se abre un momento espriritual de descolonialidad del pensamiento: la naturalización y la aceptación resignada de la desigualdad social se encuentran en retroceso. Lo típico de estos movimientos de la sociedad es la disputa por la dignidad, lo humano no reside en la desigualdad social, en lo especial y diferente, siempre justificadas por la naturalización de la superioridad del talento de ciertos individuos sobre las mayorías y de lo humano sobre la tierra, que los hacen distintos, especiales y superiores, aparece una nueva sensibilidad dotada de dignidad, todos tenemos la misma dignidad común y en la idea esencial de la igualdad social que surgen contra la humillación de ser diferente (Bauman y Bordoni 2016). En América Latina la cultura de la inequidad social empieza a perder direccionalidad y hegemonía de las formas de pensamiento, los movimientos de la sociedad se oponen radicalmente a la resignación de la desigualdad social e impugnan la desigual distribución del poder en el mundo global no solo por la negación de la integridad de ser humano y de su privación de humanidad sino, principalmente, de ser explotado y dominado por la diferencia abismal del acceso a los medios de producción como a los bienes simbólicos del orden moderno capitalista. La subjetividad que impulsan los movimientos de la sociedad está produciendo otros modos de percibir la realidad, otros modos de imaginar un mundo fundado en la justicia social y libertad de las personas más allá de la propia modernidad.

En América Latina, las poblaciones sometidas por la colonialidad y el neoliberalismo globalizado abren un nuevo horizonte epistémico alternativo al eurocéntrico, asumen la conciencia de pertenecer a un solo pueblo la humanidad, cuyo principio esencial es la dignidad (Quijano 2015). Se inaugura un inédito espíritu histórico de descolonialidad en la cultura de la reproducción de la desigualdad social.

Dinámicas que se despliegan en los márgenes del sistema moderno y de colonialidad por los movimientos de la sociedad y las experiencias inéditas que buscan restituir la vida de los sujetos en relaciones solidarias y de identidad con el planeta como las únicas formas de enfrentar las relaciones de explotación y dominación que llevan a la exclusión y destrucción del ser humano y de la naturaleza. Los movimientos de la sociedad son las fuentes de movilizaciones y transformaciones sociales, rescatan la memoria histórica de las culturas amerindias y generan "utopías reales" ${ }^{3}$ que cambian los valores y mentalidades de las personas que buscan desarrollar originales formas de vivir, nacientes identidades, enuncian proyectos autónomos de organización a partir de principios libertarios comunes que traducen las aspiraciones de una sociedad mejor, más allá de la propia acción de la mercantilización y de las diferencias sociales. En este sentido, el gran conflicto es cultural, frente a la mentalidad conservadora se desarrolla la idea de la dignidad que controvierte la injusticia, la humillación de la negación de los derechos humanos y traza la esperanza de una nueva sociedad cimentada en la igualdad.

De modo específico, en América Latina se inicia un proceso de relativización del constructo conceptual de la idea de la raza que sustentó por más de 500 años la dominación social y la negación de la ciudadanía a la mayor parte de la población por su pretendida condición natural de ser individuos pertenecientes a las "razas inferiores". Es a partir de la Segunda Guerra

4 Desarrollan experiencias de "utopías reales" y "de coste marginal cero" fundadas en relaciones sociales "democráticos igualitarios" que se desenvuelven híbridamente en el mercado y fuera del mercado, véase Erik Olin Wright (2014) y Jeremy Ryfkin (2014). 
Mundial, con la derrota del nazismo y el militarismo japonés, que se inaugura el proceso de deslegitimación de la dominación basada en torno el racismo. En especial, luego de las acciones de organización y movilización de la población indígenas de la región después de Chiapas en enero de 1994, acarrearon el cuestionamiento de toda forma de racismo y desigualdad social (Quijano 2014b).

Los movimientos medioambientalistas en su defensa del territorio y la ecología bosquejan en América Latina una cultura fundada en la dignidad que comprende lo humano como componente intrínseco de la naturaleza, que implica la recuperación cultural de su animalidad, de constituir una especie particular, de formar un ser vivo dentro de la infinita existencia heterogénea de la tierra y del universo. La dignidad proyecta un ideal que invalida la diferencia y superioridad humana, nos devuelve al mundo natural y define a todos como seres mortales e igualitarios. Los humanos tenemos que pensarnos como una especie más y común de la naturaleza para enfrentar los graves problemas que amenazan el planeta (Leff 2004, 124-185). Movimientos de la sociedad que crean un imaginario humano que resalta le valor de la igualdad en el mundo de la vida de la naturaleza.

Los movimientos de mujeres en América Latina en los últimos cincuenta ańos han transformado la conciencia sobre sí mismas (Luna 2004). Aunque el patriarcado no ha desaparecido, las mujeres tanto individual y colectivamente ya no se piensan como objetos sino como sujetos con imaginarios basados en relaciones de igualdad social y de dignidad de ser reconocidas como seres humanos con derechos. El sentimiento de dignidad se va apoderando del pensamiento de las gentes y las relaciones hombre y mujer en todos los ámbitos de la vida social se alteran y empiezan a reconstruirse en términos de los valores de igualdad social y libertad.

Los movimientos estudiantiles y juveniles, de modo específico en Chile, Brasil, México y el Perú, cuestionan las relaciones de dominio, explotación y procuran formas de igualdad social. Experiencias colectivas que demandan ser identificados como sujetos de dignidad, frente a la humillación y negación de los derechos de personas, siempre apuestan por los sueños de un mundo de igualdad social. Pero lo más importante, comienzan a transformar drásticamente las relaciones de paternidad, tradicionalmente fundadas en la autoridad suprema de origen biológica, por ser el padre quien engendra. Hoy la autoridad de la paternidad se ha convertido en un hecho moral, el hijo solo obedece y acepta la autoridad legítima del padre cuando viene acompañada de la confianza, el prestigio y la igualdad. La paternidad muestra el avance del valor de la igualdad en la sociedad del siglo XXI.

Los nuevos movimientos de indignados que recorren el planeta, desde América Latina (Castells 2012), el norte del África, Europa y los Estados Unidos, instalan demandas de igualdad social como la aspiración central frente a la extrema polarización social del mundo neoliberal, graficado en el " $1 \%$ más rico" que se apropia del $99 \%$ de la riqueza global. Movimiento que viene produciendo un cambio fundamental en las mentalidades de las gentes sobre la indignidad de la inmensa diferenciación social, la mayor de la historia humana, y desarrollan nuevos valores y juicios en torno a la dignidad humana, de un imaginario ide igualdad y justicia social.

En América Latina nuevamente se recrean valores de igualdad social que posibilitan la irrupción de otra episteme, traduciendo el desarrollo de un horizonte de sentido histórico alternativo. Hoy se bosqueja un inédito proceso cultural como parte inmanente de su encuentro con las ideas de igualdad social. Bauman $(2014,113)$ lo expresa claramente: "Si preguntáramos a la gente por los valores más importantes para ellos, es muy probable que muchos contesten nombrando la igualdad".

En general, la nueva cultura histórica de la dignidad emerge como un nuevo sentido societal fundamentado en la responsabilidad y solidaridad entre nosotros y la naturaleza, además de reconocer el comportamiento particular de los seres humanos. La dignidad es el valor que representa los derechos y la igualdad social de las personas.

La cultura de la dominación y la desigualdad social están en cuestión en Latinoamérica, se desarrollan formas de pensamiento originales, ya no parten de la justificación de las desigualdades sociales, empiezan a germinar discursos epistémicos alternos y se abren a un proceso de descolonialidad de la cultura y el poder. La emergencia epistémica facilita ir más allá de los límites de la modernidad y la colonialidad, la memoria y la imaginación hilvanan una posibilidad de existencia social diferente. Es en América Latina donde empieza a desarrollarse la epistémica que cuestiona el modo de pensar europeísta, porque es el espacio primero y de fundación del proceso histórico del sistema de modernidad global (Quijano 2015). 


\section{Conclusión}

La modernidad capitalista se apertura y, pareciera que, llega a sus límites con el mismo debate sobre la dignidad de la humanidad. En efecto, en los albores de la modernidad Giovanni Pico Della Mirandola escribió su famoso Discurso sobre la dignidad del hombre (1486), rescatando la autonomía de lo humano y la igualdad de derechos. En la actualidad, en momentos de la mayor desigualdad de la historia de la humanidad y, probablemente, en los desenlaces de la modernidad recuperamos el Discurso sobre la dignidad, los seres humanos somos partes de la naturaleza, somos "Múltiples culturas, una sola humanidad" (Bauman 2008), un solo pueblo y la dignidad es el mayor valor de la igualdad social.

La cuestión central sobre la vida social formulada por Freud, en el tiempo presente adquiere un contenido diferente. Se trata de un momento de grandes cambios societales, no obstante gira en torno la cultura de la desigualdad social y la cultura de la dignidad que marca todo el escenario contemporáneo. Nuevo espíritu que adelanta un proceso histórico basado en la descolonialidad de la cultura de la desigualdad social.

En América Latina el discurso alegórico de la dignidad empieza a corroer los cimientos del modo de organización de la sociedad en torno a las jerarquías sociales y posibilita pensar en el largo plazo en un original horizonte histórico que imagine una sociedad estructurada según los principios de la libertad e igualdad social.

\section{Referencias bibliográficas}

Aguilera, O. (2016): Movidas, movilizaciones y movimientos. Cultura politica y politicas de las culturas juveniles en el Chile de hoy, Ril editores: Santiago.

Bauman, Z. (2014). ¿La riqueza de unos pocos no beneficia a todos?, Paidós: Bogotá.

Bauman, Z. y Bordoni C. (2016). Estado de crisis, Paidós: Bogotá.

Bauman, Z. y Donskis, L. (2013): Cegueira moral. A perda da sensibilidades na modernidade líquida. Zahar: Rio de Janeiro.

Bauman, Z. (2011): Daños colaterales. Desigualdades sociales en la era global. FCE: México.

Bauman, Z. (2008): Múltiples culturas, una sola humanidad. Katz - CCCB: Barcelona.

Bauman, Z. (2000). Trabajo, consumismo y nuevos pobres. Gedisa: Barcelona.
BEck, U. (1997). La sociedad del riesgo mundial: en busca de la seguridad perdida. Paidós: Madrid.

Bourdieu, P. (1980). "Le capital social. Notes provisoires", Actes de la Recherche en Sciences Sociales, Vol. 31, http:// www.persee.fr/web/revues/home/prescript/article/ arss_0335-5322_1980_num_31_1_2069

Castells, M. (2012). Redes de indignación y esperanza. Los movimientos sociales en la era de internet. Alianza: Madrid.

Castells, M. (2015). "Sociedades polarizadas", La Vanguardia, 17 de octubre: Barcelona, http://www.caffereggio. net/2015/10/17/sociedades-polarizadas-de-manuel-castells-en-la-vanguardia/

Ceballos G.; Ehrlich, P. R.; Barnosky, A.; Andrés García, A; Pringle, R. M. y Palmer, T. M. (2015) "Accelerated modern human-induced species losses: Entering the sixth mass extinction", Science Advances, Vol. 1, N 5 , http://advances.sciencemag.org/content/advances/1/5/ e1400253.full.pdf

De Hoyos, R.; Rogers, H. y Székely, M. (2016). NiNis en América Latina 20 millones de jóvenes en busca de oportunidades. Banco Mundial: Washington.

De Soto, H. (2016). "El 'impasse' mexicano del Santo Padre", El Comercio, Portafolio,14 de febrero de 2016: Lima.

Dussel, E. (2002/2003). "Estado de guerra" permanente y razón cínica”, Revista Herramienta, No 21: Buenos Aires.

Fernández-Maldonado, E. (2015). La rebelión de los pulpines. Jóvenes, trabajo y política. Otra Mirada: Lima.

Freud, S. (2013). El malestar en la cultura. Alianza: Madrid.

García Canclini, N. (2007). Las nuevas desigualdades y su futuro. https://ceas.files.wordpress.com/2007/03/1-canclini.pdf

González, R. y Schneider, A. (comps.) (2016). Sociedades en conflicto. Movimientos sociales y movimientos armados en América Latina. CLACSO: Buenos Aires.

Kristeva, J. (1999). El porvenir de la revuelta. FCE: Buenos Aires.

Hinkelammert, F. \& Mora, H. (2005). Hacia una economía para la vida. DEI: San José.

Hinkelammert, F. (2003). Solidaridad o suicidio colectivo, Ambientico ediciones: Heredia - Costa Rica.

Jaspers, K. (1968). Origen y meta de la historia. Revista de Occidente: Madrid.

LefF, E. (2004). Racionalidad ambiental. La reapropiación social de la naturaleza. Siglo XXI: México.

Lipovetsky, G. (2003). La era del vacio: ensayos sobre el individualismo contemporáneo. Anagrama: Madrid.

Luna, L. (2004). Los movimientos de mujeres en América Latina y la renovación de la historia, fem-e-libros: México. 
Mejía, J. (2016). América Latina, modernidad y conocimiento. El desarrollo de otro discurso epistémico. Facultad de Ciencias Sociales UNMSM: Lima.

Mejía, J. (2015). "Corrupción, violencia y cinismo. Notas sobre la insensibilidad moral en el Perú”, en Ledesma, M. Justicia, derecho y sociedad. Debates interdisciplinario para el análisis de la justicia en el Perú. Tribunal Constitucional del Perú: Lima.

Mejía, J. (2014). Sociedad, consumo y ética. El Perú en tiempos de globalización, Facultad de Ciencias Sociales UNMSM: Lima.

Morin, E. (2011). La vía. Para el futuro de la humanidad, Paidós: Barcelona.

NASA (2015). NOAA Analyses Reveal Record-Shattering Global Warm Temperatures in 2015, http://www.nasa.gov/ press-release/nasa-noaa-analyses-reveal-record-shattering-global-warm-temperatures-in-2015

Pico della Mirandola, G. (2006). Discurso sobre la dignidad del hombre. Editorial $\pi$ : Medellín

PNUD (2013). Informe Regional de Desarrollo Humano 20132014. Seguridad Ciudadana con rostro humano: diagnóstico y propuestas para América Latina. PNUD: New York.

Quijano, A. (2015): "Notas sobre la descolonialidad del poder", Yuyaykusun, No 8, Universidad Ricardo Palma: Lima.

Quijano A. (2014a). "Bien vivir: entre el "desarrollo" y la des/colonialidad del poder", en Antología esencial. De la dependencia histórico-estructural a la colonualidadldescolonialidad del poder. CLACSO: Buenos Aires.
Quijano A. (2014b). "El 'movimiento indígena' y las cuestiones pendientes en América Latina”, en Antología esencial. De la dependencia histórico-estructural a la colonialidadl descolonialidad del poder. CLACSO: Buenos Aires.

Rojas, J. (2012). Sociedad bloqueada Movimiento estudiantil, desigualdad y despertar de la sociedad chilena. RiL: Santiago.

Ryfkin, J. (2014). La sociedad de coste marginal cero. El internet de las cosas y el eclipse del capitalismo. Paidós: Barcelona.

Sandoval, R.; Alonso, J.; De Sousa, B; Castells, M; Holloway, J; Zibechi, R.; Gutiérrez, R.; López y Rivas, G.; Esteva, G.; Manero, R.; Rozental, E. y AlmenDRA, V. (2015). Pensar desde la resistencia anticapitalista y la autonomía. CIESAS: México.

Sartori, G. (1998). Homo videns. La sociedad teledirigida. Taurus: Madrid.

Sloterdijk, P. (2003). Crítica de la razón cínica. Ediciones Siruela: Madrid.

Ubilluz, J. C. (2006). Los nuevos súbditos. Cinismo y perversión en la sociedad contemporánea. IEP: Lima.

Wallerstein, 1. (2010). "Latinoamérica y los movimientos antisistémicos", en Toni Negri y otros: I Ciclo de seminarios internacionales. Pensando desde Bolivia. Vicepresidencia del Estado Plurinacional de Bolivia: La Paz.

Wright, E. O. (2014). Construyendo utopias reales, Akal: Madrid.

Zibechi, R. (2015). Descolonizar el pensamiento crítico y las prácticas emancipatorias, Ediciones desde abajo: Bogotá. 